\title{
Titanium Dioxide Nanoparticles: Synthesis, X-Ray Line Analysis and Chemical Composition Study
}

\author{
Hossein Mahmoudi Chenari ${ }^{a *}$, Christoph Seibel ${ }^{b, c}$, Dirk Hauschild ${ }^{b, c}$, Friedrich Reinert $^{b, c}$, Hossein \\ Abdollahiand $^{d}$ \\ ${ }^{a}$ Department of Physics, Faculty of Science, University of Guilan, Namjoo Ave, Po Box 41335-1914, Rasht, Iran \\ ${ }^{b}$ Experimental Physics VII and Röntgen Research Center for Complex Materials - RCCM, Universität \\ Würzburg, Am Hubland, D-97074 Würzburg, Germany \\ ${ }^{c}$ Karlsruhe Institute of Technology - KIT, Gemeinschaftslabor für Nanoanalytik, D-76021 Karlsruhe, \\ Germany \\ ${ }^{d}$ Nanotechnology Research Center of Urmia University, Urmia, Iran
}

Received: April 08, 2016; Revised: July 25, 2016; Accepted: August 26, 2016

\begin{abstract}
$\mathrm{TiO}_{2}$ nanoparticleshave been synthesized by the sol-gel method using titanium alkoxide and isopropanolas a precursor. The structural properties and chemical composition of the $\mathrm{TiO}_{2}$ nanoparticles were studied usingX-ray diffraction, scanning electron microscopy, and X-ray photoelectron spectroscopy. The X-ray powder diffraction pattern confirms that the particles are mainly composed of the anatase phase with the preferential orientation along [101] direction. The physical parameters such as strain, stress and energy density were investigated from the Williamson- Hall (W-H) plot assuming a uniform deformation model (UDM), and uniform deformation energy density model (UDEDM). The W-H analysis shows an anisotropic nature of the strain in nanopowders. The scanning electron microscopy image shows clear $\mathrm{TiO}_{2}$ nanoparticles with particle sizes varying from 60 to $80 \mathrm{~nm}$. The results of mean particle size of $\mathrm{TiO}_{2}$ nanoparticles show an inter correlation with the $\mathrm{W}$ - $\mathrm{H}$ analysis and SEM results. Our X-ray photoelectron spectroscopy spectra show that nearly a complete amount of titanium has reacted to $\mathrm{TiO}_{2}$.
\end{abstract}

Keywords: $\mathrm{TiO}_{2}$;Nanoparticles; $X$-ray analysis;SEM;XPS

\section{Introduction}

Nanometer-scale materials have recently attracted considerable scientific attention because of their beneficial high surface to volume ratio and therefore unique chemical, electronic, and physical properties. In particular $\mathrm{TiO}_{2}$ nanoparticles are in the focus of research and thus many reports on electrical, optical, and structural properties of $\mathrm{TiO}_{2}$ nanoparticles can be found ${ }^{1-4}$. B. Sathyaseelanet al. ${ }^{5}$ investigated structural, optical and morphological properties of post-growth calcined $\mathrm{TiO}_{2}$ nanopowder. The size dependent reflective properties of $\mathrm{TiO}_{2}$ nanoparticles synthesizedusing arc discharge method were studied by F. Fang et al. ${ }^{6}$ Nanocrystalline $\mathrm{TiO}_{2}$ is a promising candidate for a wide range of applications such as photocatalysis, solar cells, dielectric materials, and photoconductors ${ }^{7-10}$. Modification of $\mathrm{TiO}_{2}$ with metal and nonmetal elements has received much attention and Doped $\mathrm{TiO}_{2}$ nanoparticles exhibit novel properties and according to impurity type, dopants improve the physical and optoelctronic paroperties of $\mathrm{TiO}_{2}$ nanoparticles. For instance, K. Kaviyarasu et al. ${ }^{11}$ reported the fabrication, optical and microscopic studies of magnesium doped $\mathrm{TiO}_{2} \mathrm{NCs}$.optical, structural, and electronic properties of carbon-modified titanium dioxide nanoparticles synthesized by ultrasonic

\footnotetext{
* e-mail: mahmoudi hossein@guilan.ac.ir and h.mahmoudiph@gmail.com
}

nebulizer spray pyrolysis have been investigated by $\mathrm{R}$. Taziwa et al. ${ }^{12} \mathrm{~S}$. Ivanov et al. ${ }^{13}$ studied one-step synthesis of $\mathrm{TiO}_{2}$ nanoparticles based on the interaction between thiourea and metatitanic acid and reported the photocatalytic activity of the doped $\mathrm{SC}_{-} \mathrm{TiO}_{2}$ powders. $\mathrm{TiO}_{2}$ nanoparticles in both powder and film form can be synthesized using various methods such as chemical vapor deposition ${ }^{14}$, chemical spray pyrolysis $^{15}$, sol-gel technique ${ }^{16}$, hydrothermal treatment ${ }^{17}$, and arc discharge method ${ }^{18}$. In this paper, the sol-gel technique has been successfully employed to synthesize $\mathrm{TiO}_{2}$ particles on the nanometer scale.

Most of the research reports on the structural properties of nanoparticles dealt with the determination of structure type, physical and different microstructural parameters. $\mathrm{X}$-ray diffraction line broadening studies give more useful information about the physical parameters such as crystallite size, dislocation density and strain. There are many analytical methods to evaluate the microstructure properties of materials such as the Scherrer's equation ${ }^{19}$, Williamson-Hall analysis ${ }^{20}$, the integral breadth method ${ }^{21}$ and size strain plot method ${ }^{22}$. This study highlightsthe microstructure analysis and chemical composition of $\mathrm{TiO}_{2}$ nanoparticles. Whereas only a few reports on $\mathrm{TiO}_{2}$ nano-crystals perform X-ray photoelectron spectroscopy (XPS) ${ }^{23-26}$. 
In this work, $\mathrm{TiO}_{2}$ nanocrystals were prepared by a simple sol-gel method. A structural characterization and chemical composition study was performed by X-ray diffraction, scanning electron microscopy, and X-ray photoelectron spectroscopy. We give more information on strain-stress and the energy density of crystal by using the Williamson- Hall procedure. We also include a quantitative analysis of chemical composition of a very successful synthesized nanoparticle by surface sensitive XPS known as electron spectroscopy for chemical analysis (ESCA). The measurements suggest that nearly a complete amount of titanium has reacted to $\mathrm{TiO}_{2}$.

\section{Experimental Methods}

\subsection{Preparation}

The preparation of $\mathrm{TiO}_{2}$ nanoparticles was performed by the sol-gel method as follows:

The high reactivity of alkoxides in the presence of water or solutions containing isopropanol causes a formation of three-dimensional oxide networks, producing metal hydroxides (i) or hydrated oxides (ii). Hence, the general chemical reactions are given by the following equations:

$$
\begin{aligned}
& \mathrm{Ti}(\mathrm{OR})_{4}+4 \mathrm{H}_{2} \mathrm{O} \rightarrow \mathrm{Ti}(\mathrm{OH})_{4}+ \\
& 4 \mathrm{ROH}(\text { hydrolysis }),(\mathrm{I}) \\
& \mathrm{Ti}(\mathrm{OH})_{4} \rightarrow \mathrm{TiO}_{2} \times \mathrm{H}_{2} \mathrm{O}+ \\
& (2-\mathrm{x}) \mathrm{H}_{2} \mathrm{O} \text { (condensation), (II) }
\end{aligned}
$$

Where $\mathrm{R}$ is ethyl, i-propyl, n-butyl, etc. ${ }^{27}$. The molar ratio of water to titanium strongly affects the stability, shape, size, and morphology of the produced alkoxide-sol. Also the size distribution of nanoparticles is dependent on the $\mathrm{pH}$ of solution ${ }^{28}$. Due to the high reactivity of titanium alkoxide ( $\left.\mathrm{Ti}\left\{\mathrm{OCH}\left(\mathrm{CH}_{3}\right)_{2}\right\}_{4}\right), 10 \mathrm{ml}$ of this precursor was diluted with $40 \mathrm{ml}$ of isopropanol $\left(\mathrm{C}_{3} \mathrm{H}_{7} \mathrm{OH}\right)$ at room temperature in a dry atmosphere with about $8 \%$ relative humidity. The mixture was then added dropwise into a solution that consist of deionized water and isopropanol in a $1: 1$ ratio. For adjustment of the $\mathrm{pH}$ valuehydrochloric acid and ammonium hydroxide were added, respectively. With this addition, the acidity-alkalinity of the gel was stabilized to a $\mathrm{pH}$ value of 3 . Subsequently, the solution was vigorously stirred for 30 minutes and a yellowish gel was formed. Afterwards, the prepared materials were washed with ethanol and the obtained gel was then dried at $120^{\circ} \mathrm{C}$ for two hours. A Scientific furnace(NaberthermLVD $73 / 23 / \mathrm{EC}$ ) was used for calcinations of the synthesized materials at $450^{\circ} \mathrm{C}$ for four hours ${ }^{29}$. The resulting product was $\mathrm{TiO}_{2}$ nanopowder. We will now begin to discuss the results of the structure analysis and the chemical composition measurements.

\subsection{Characterization techniques}

The bulk sensitive X-ray diffraction (XRD) patterns were taken with Philips X'Pertdiffractometerat room temperature using monochromatic $\mathrm{Cu} \mathrm{K \alpha}(\mathrm{h} v=8042.55 \mathrm{eV})$ excitation. Measurements were taken under beam acceleration conditions of $40 \mathrm{kV} / 35 \mathrm{~mA}$. Whereas the surface sensitive X-ray photoelectron spectroscopy (XPS) measurements were performed under ultra-high vacuum (UHV) condition, in a system exhibiting a base pressure of better than $2 \times 10^{-10} \mathrm{mbar}$. In order to study the chemical state of titanium and oxygen in the nanoparticles we used a standard non-monochromatized $\mathrm{Mg} \mathrm{K} \alpha(\mathrm{h} v=1253.6 \mathrm{eV}) \mathrm{X}$-ray source and a VG Clam 4 electron spectrometer. The spectra were corrected for X-ray satellites and secondary electron background $\left(\right.$ Shirley $\left.{ }^{30}\right)$ prior to analysis. Scanning electron microscopy (SEM) images of the same samples were recorded with a LED-1430VP microscope using an electron beam energy of $15 \mathrm{keV}$ and a beam current of $2.62 \mathrm{~A}$.

\section{Results and Discussion}

\subsection{X-ray analysis}

X-ray profile analysis is apowerfultoolin extracting the microstructure information of nanocrystallinesamples. Figure 1 shows the XRD pattern of $\mathrm{TiO}_{2}$ nanoparticles, in the $2 \theta$ range of $10-70^{\circ}$. The diffraction peaks corresponding to the (1 $\left.\begin{array}{lll}1 & 1\end{array}\right),\left(\begin{array}{lll}0 & 0 & 4\end{array}\right),\left(\begin{array}{lll}2 & 0 & 0\end{array}\right),\left(\begin{array}{lll}1 & 0 & 5\end{array}\right),\left(\begin{array}{lll}2 & 1 & 1\end{array}\right),\left(\begin{array}{lll}2 & 0 & 4\end{array}\right)$ and (1 06 ) crystal planes with the lattice constants $\mathrm{a}=3.755 \AA$ and $\mathrm{c}=9.5114 \AA$ confirms the anatase phases of the $\mathrm{TiO}_{2}$ nanoparticles according to the JCPDS file 21-1272 ${ }^{31}$. X-ray diffraction profiles are usually influenced by crystallite size and lattice strain. According to the W-H method the individual contribution due to the size and strain can be expressed as ${ }^{17}$

$$
\begin{gathered}
\mathrm{B}_{\mathrm{hkl}}=\mathrm{B}_{\mathrm{S}}+\beta_{\mathrm{D}} \\
\mathrm{B}_{\mathrm{hkl}} \operatorname{Cos} \theta=(\mathrm{k} \lambda / \mathrm{D})+4 \varepsilon \sin \theta
\end{gathered}
$$

Where $\varepsilon$ is the strain and D is the average crystallite size of a x-ray peak. $B_{h k l}$ is the peak width at half-maximum intensity and $\mathrm{B}_{\mathrm{s}}, \beta_{\mathrm{D}}$ are the peak broadeningduetothe crystallite size and lattice strain,respectively.In the Eq. 2 the strain was assumed to be uniform in all crystallographic direction implying a uniform deformation model ('UDM'). Figure 2 (a) shows the UDM analysis. The effective crystallite size can be estimated from the extrapolation of $B_{h k l} \cos \theta$ versus $4 \sin \theta$ and the slop of the fitted line represents the strain.Inthe uniform deformation energy density model (UDEDM)has been replaced by $\varepsilon=\sigma / E$ in equation (2); where $\sigma$ is the stress of crystal and $\mathrm{E}$ is the modulus of elasticity in the direction perpendicular to the set of Bragg reflection. The elastic 
moduli $\mathrm{E}$, for the $\mathrm{TiO}_{2}$ anatase-tetragonal assumed to be $\approx 174 \mathrm{GPa}^{32}$. In the modified form of $\mathrm{W}-\mathrm{H}$ equation called (UDEDM) model, the strain energy density $\mathrm{u}$ is considered and the modulus of elasticity is no longer independent. The energy density $u$ can be determined from $u=\left(\varepsilon^{2} E\right) / 2$ using Hooke's law. Then equation (2) can be modified again according to the energy density as

$$
\begin{aligned}
& \mathrm{B}_{\mathrm{hkl}} \operatorname{Cos} \theta=(\mathrm{k} \lambda / \mathrm{D})+ \\
& \left(4 \sin \theta \times\left(2 \mathrm{u} / \mathrm{E}_{\mathrm{hkl}}\right)^{1 / 2}\right)
\end{aligned}
$$

In this model $\mathrm{B}_{\mathrm{hkl}} \cos \theta$ were plotted against $4 \sin \theta /$ $\left(E_{h k l} / 2\right)^{1 / 2}$. The anisotropic energy density $(u)$ from the slope of fitted line and the crystallite size calculated from the y-intercept; see Figure 2(b). The results obtained from the UDM and UDEDM models are collected in Table 1.As it is evidentfromTable1, the mean crystallite sizes obtained from the W-H models are more or less similar implying that strain in different form has very small contribution on the mean crystallite size.

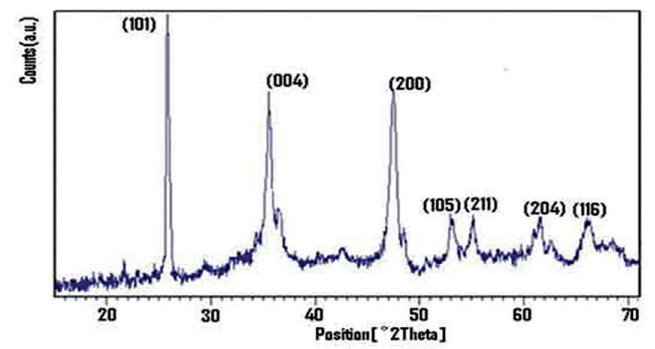

Figure 1: X-raydiffraction pattern of $\mathrm{TiO}_{2}$ nanoparticles
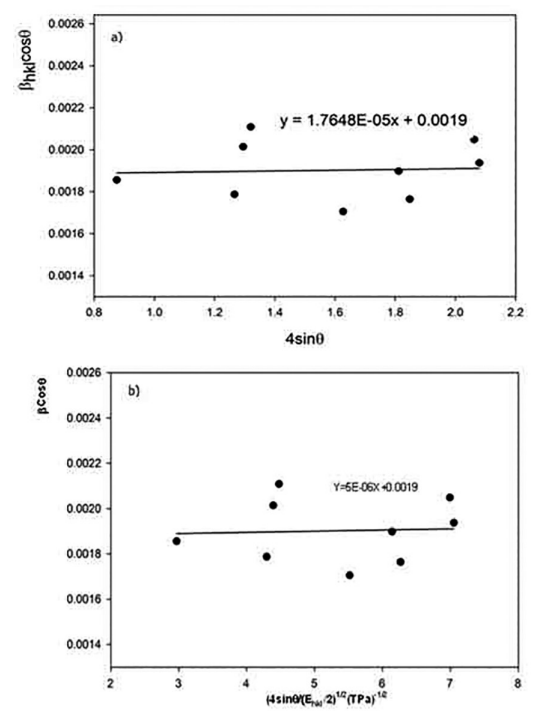

Figure 2: The $\mathrm{W}-\mathrm{H}$ analysis of $\mathrm{TiO}_{2}$ nanoparticles assuming (a) UDM, and (b) UDEDM model.
Table 1: Micro structural parameters of $\mathrm{TiO}_{2}$ nanoparticles.

\begin{tabular}{lccccc}
\hline \multicolumn{2}{c}{ UDM model } & \multicolumn{4}{c}{ UDEDM model } \\
$\mathrm{D}$ & $\varepsilon$ & $\mathrm{D}$ & $\mathrm{u}$ & $\varepsilon$ & $\sigma(\mathrm{MPa})$ \\
$(\mathrm{nm})$ & $($ no unit $)$ & $(\mathrm{nm})$ & $\left(\mathrm{Kj}^{-3} \mathrm{~m}^{-3}\right)$ & $($ no unit $)$ & \\
\hline 72.2 & $2 \times 10^{-5}$ & 72.2 & 5.2054 & $5.469 \times 10^{-6}$ & 0.952 \\
\hline
\end{tabular}

\subsection{SEManalysis}

Figure 3 shows SEM image obtained from the titanium oxide nanoparticles. The structure of this particle cluster consisting of agglomerated nanoparticles can be identified as a non-ordered and porous. In Figure 3,two particle sizes were exemplarily determined, exhibiting width of 64.82 $\mathrm{nm}(\mathrm{Pa} 1)$ and $74.08 \mathrm{~nm}(\mathrm{~Pa} 2)$. In general, the width of the nanoparticles varies from 60 to $80 \mathrm{~nm}$.

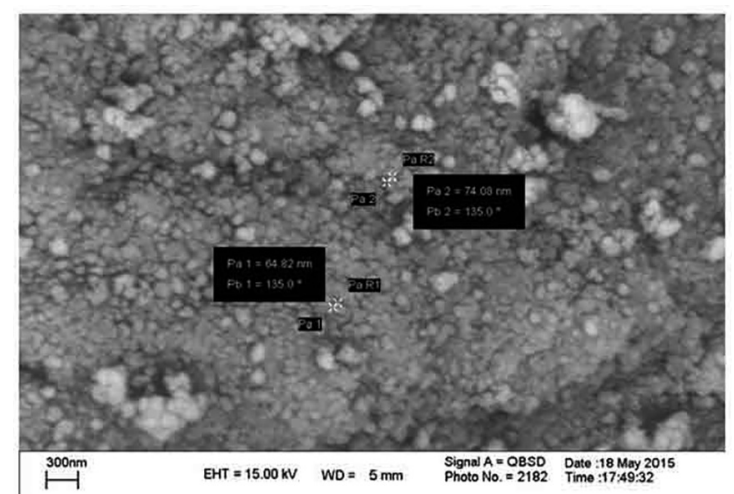

Figure 3: SEM image of the $\mathrm{TiO}_{2}$ nanoparticles.

\subsection{X-ray photoelectron spectroscopy}

The powder was prepared ex-situ before transferring to the UHV chamber. Subsequent, X-ray photoelectron spectroscopy was performed and a survey scan of $\mathrm{TiO}_{2}$ nanopowder is presented in Figure 4. To compensate charging effects, we calibrated the $\mathrm{C} 1 \mathrm{~s}$ peak to $286.0 \mathrm{eV}$ since at this certain binding energy $\mathrm{C}-\mathrm{N}$ and $\mathrm{C}-\mathrm{O}$ bonds overlap energetically [25].The spectrum is dominated by the signals of Ti and $\mathrm{O}$. The binding energies of the spin-orbit split Ti2 $\mathrm{p}_{1 / 2,3 / 2}(464.6 \mathrm{eV}$ and $458.9 \mathrm{eV}$, respectively) signals, as well as the $\mathrm{O} 1 \mathrm{~s}$ (530.7 $\mathrm{eV}$ ) level are corresponding to the titanium dioxide chemical environment (see Table 2).In addition, we find a significant amount of carbon (see C 1s in Figure 4) and nitrogen (see $\mathrm{N}$ 1sin Figure 4) in the spectrum. The detected carbon and nitrogen contaminations stem probably from adsorbents at grain boundaries and crystallite surfaces. In general, contaminations are inevitable for samples exposed to air. However,the residual build-in contaminations resulting from the manufacturing process cannot be rule out. Furthermore, we derived the Ti:O ratio at the particle surfaces by using the corresponding cross 


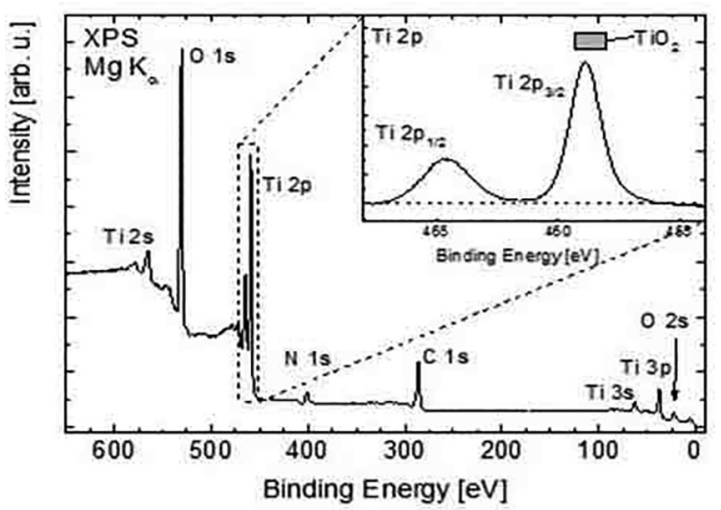

Figure 4: X-ray photoemission spectrum of $\mathrm{TiO}_{2}$ nanoparticles taken at room temperature using a $\mathrm{Mg} \mathrm{X}$-ray source.

Table 2: Energetic positions of the Ti $2 \mathrm{p}_{1 / 2}, \mathrm{Ti} 2 \mathrm{p}_{3 / 2}$, and $\mathrm{O} 1 \mathrm{~s}$ of the investigated nanoparticle sample and adsorbate. Literature values are added for comparison.

\begin{tabular}{lccc}
\hline Element & Orbital & $\mathrm{E}_{\mathrm{B}, \text { Exp }}(\mathrm{eV})$ & $\mathrm{E}_{\mathrm{B}, \mathrm{Lit}}(\mathrm{eV})$ \\
\hline Titanium & $2 \mathrm{p}_{1 / 2}$ & 464.6 & $464.3^{34}, 464.4^{35}$ \\
Titanium & $2 \mathrm{p}_{3 / 2}$ & 458.9 & $458.8^{34,35}$ \\
Oxygen & $1 \mathrm{~s}$ & 530.7 & $529.6^{34}, 528.4^{35}$ \\
\hline
\end{tabular}

section $^{26}$, the inelastic mean free path ${ }^{33}$, and the transmission function $\mathrm{T} \sim \mathrm{E}_{\mathrm{kin}}{ }^{-\mathbf{0 . 6}}$ of our electron spectrometer. Hence, we determined a total Ti:O ratio of $1:(2.2 \pm 0.4)$. We explain the slightly surplus of the oxygen content with adsorbents like $\mathrm{CO}_{\mathrm{x}}$ and hydro carbons. A detailed analysis of the O1s signal reveals a small deviation from its intrinsic lineshape, which indicates several oxygen species. However, it is beyond the aim of this paper to evaluate their individual quantities and to assign them to certain contaminations. The inset of Figure 4 shows the detailed measurement of the Ti $2 p$ region with the spin-orbit split doublet peaks at $463.9 \mathrm{eV}$ and $458.2 \mathrm{eV}$ for $\mathrm{Ti}$ $2 \mathrm{p}_{1 / 2}$ and Ti $2 \mathrm{p}_{3 / 2}$, respectively. A comparison of the obtained binding energies to the respective literature values for Ti $2 p$ shows a good agreement between the binding energy of the main spectral $2 \mathrm{p}$ component and the one of pure $\mathrm{TiO}_{2}$ (see Table 2$)^{34,35}$. Furthermore, the absence of a signal at lower binding energies of approximately $453.8 \mathrm{eV}^{36}$ indicates that during the synthesis in the frame of measurement accuracy and probing depth all Ti atoms have fully reacted to titanium dioxide. The inset shows a detailed spectrum of the Ti $2 \mathrm{p}$ signal with a subtracted Shirley background and therefore a dashed horizontal line indicates the base line. The grey bar represents the reported $\mathrm{Ti} 2 \mathrm{p}_{3 / 2}$ binding energy values for $\mathrm{TiO}_{2}{ }^{35}$.

\section{Conclusions}

In this study, we have successfully prepared titanium dioxide nanoparticles applying sol-gel technique. The performed X-ray diffraction measurement suggests that the precursor materials have reacted to the anatase phase. The evolution of the crystallite size and the microstrain was studied using the X-ray peak broadening analysis by the Williamson-Hall method. The obtained mean crystallite size of $\mathrm{TiO}_{2}$ nanoparticles show an inter correlation with the value obtained from the W-H analysis and SEM results. The results of the surface sensitive X-ray photoelectron spectroscopy measurements indicate that nearly the complete amount of titanium has reacted to $\mathrm{TiO}_{2}$.

\section{Acknowledgments}

The authors would like to acknowledge the Experimental Physics VII and Röntgen Research Center for Complex Materials (RCCM),UniversitätWürzburg, Am Hubland, D-97074 Würzburg, Germany and University of Guilan Research Council for the support of this work.

\section{References}

1. Harizanov O, Harizanova A. Development and investigation of sol-gel solutions for the formation of $\mathrm{TiO}_{2}$ coatings. Solar Energy Materialsand Solar Cells. 2000;63(2):185-195.

2. Li B, Wang X, Yan M, Li L. Preparation and characterization of nano-TiO, powder. Materials Chemistry and Physics. 2002;78(1):184-188.

3. Kitiyanan A, Ngamsinlapasathian S, Pavasupree S, Yoshikawa S. The preparation and characterization of nanostructured $\mathrm{TiO}_{2}-$ $\mathrm{ZrO}_{2}$ mixed oxide electrode for efficient dye-sensitized solar cells. Journal of Solid State Chemistry. 2005;178(4):1044-1048.

4. Yu C, Park J. Thermal annealing synthesis of titanium-dioxide nanowire-nanoparticle hetero-structures. Journal of Solid State Chemistry. 2010;183(10):2268-2273.

5. Sathyaseelan B, Manikandan E, Lakshmanan V, Baskaran I, Sivakumar K, Ladchumananandasivam R, et al. Structural, optical and morphological properties of post-growth calcined $\mathrm{TiO}_{2}$ nanopowder for opto-electronic device application: Ex-situ studies. Journal of Alloys and Compounds. 2016;671:486-492.

6. Fang F, Kennedy J, Carder D, Futter J, Rubanov S. Investigations of near infrared reflective behaviour of $\mathrm{TiO}_{2}$ nanopowders synthesized by arc discharge. Optical Materials. 2014;36(7):1260-1265.

7. Santangelo S, Messina G, Faggio G, Donato A, De Luca L, Donato $\mathrm{N}$, et al. Micro-Ramananalysis of titanium oxide/carbonnanotubesbased nanocomposites for hydrogen sensing applications. Journal of Solid State Chemistry. 2010;183(10):2451-2455.

8. Morris D, Egdell RG. Application of V-doped $\mathrm{TiO}_{2}$ as a sensor for detection of $\mathrm{SO}_{2}$. Journal of Materials Chemistry. 2001;11:3207-3210.

9. Xu X, Zhao J, Jiang D, Kong J, Liu B, Deng J. TiO 2 sol-gel derived amperometric biosensor for $\mathrm{H}_{2} \mathrm{O}_{2}$ on the electropolymerized phenazine methosulfate modified electrode. Analytical and Bioanalytical Chemistry. 2002;374(7):1261-1266.

10. Ding Z, Hu X, Lu GQ, Yue PL, Greenfield PF. Novel Silica Gel Supported $\mathrm{TiO}_{2}$ Photocatalyst Synthesized by CVD Method. Langmuir. 2000;16(15):6216-6222. 
11. Kaviyarasu K, Premanand D, Kennedy J, Manikandan E. Synthesis of mg doped $\mathrm{TiO}_{2}$ nanocrystals prepared by wetchemical method: optical and microscopic studies. International Journal of Nanoscience.2013;12(5):1350033.

12. Taziw R, Meyer EL, Sideras-Haddad E, Erasmus RM, Manikandan E, Mwakikunga BW. Effect of Carbon Modification on the Electrical, Structural, and Optical Properties of $\mathrm{TiO}_{2}$ Electrodes and Their Performance in Labscale Dye-Sensitized Solar Cells. International Journal of Photoenergy. 2012;2012:904323.

13. Ivanov S, Barylyak A,Besaha K, Bund A, Bobitski Y, WojnarowskaNowak R, et al. Synthesis, Characterization, and Photocatalytic Properties of Sulfur- and Carbon-Codoped $\mathrm{TiO}_{2}$ Nanoparticles. Nanoscale Research Letters. 2016;11:140.

14. Wang Y, HaoY, Cheng H, Ma J, Xu B, Li W, et al.The photoelectrochemistry of transition metal-ion-doped $\mathrm{TiO}_{2}$ nanocrystalline electrodes and higher solar cell conversion efficiency based on $\mathrm{Zn} 2+$-doped $\mathrm{TiO}_{2}$ electrode. Journal of Materials Science. 1999;34(12):2773-2779.

15. Li X, Chen G, Po-Lock Y, Kutal C. Photocatalytic oxidation of cyclohexane over $\mathrm{TiO}_{2}$ nanoparticles by molecular oxygen under mild conditions. Journal of Chemical Technology and Biotechnology. 2003;78(12):1246-1251.

16. Hemissi M, Amardjia-Adnani H.Optical and Structural properties of titanium oxide thin films prepared by sol-gel methods. Digest Journal of Nanomaterials and Biostructures. 2007;2(4):299-305.

17. Reddy KM, Manurama SV, Reddy AR. Bandgap studies on anatase titanium dioxide nanoparticles. Materials Chemistry and Physics. 2002;78(1):239-245.

18. Fang F, Kennedy J, Manikandan E, Futter J, Markwitz A. Morphology and characterization of $\mathrm{TiO}_{2}$ nanoparticles synthesized by arc discharge. Chemical Physics Letters. 2012;521:86-90.

19. Scherrer P. Bestimmung der Größe und der inneren Struktur von Kolloidteilchen mittels Röntgenstrahlen. Nachrichten von der Gesellschaft der Wissenschaften zu Göttingen, MathematischPhysikalische Klasse. 1918;1918:98-100.

20. Williamson GK, Hall WH. X-ray line broadening from filed aluminium and wolfram. Acta Metallurgica. 1953;1(1):22-31.

21. Santra K, Chatterjee P, Sen Gupta SP. Voigt modelling of sizestrain analysis: Application to $\alpha-\mathrm{Al}_{2} \mathrm{O}_{3}$ prepared by combustion technique. Bulletin of Materials Science. 2002;25(3):251-257.

22. Prabhu YT, Venkateswara Rao K, Sesha Sai Kumar V, Siva Kumari B. X-ray Analysis of Fe doped ZnO Nanoparticles by Williamson-Hall and Size-Strain Plot. International Journal of Engineering and Advanced Technology. 2013;2(4):268-274.
23. Madhu Kumar P, Badrinarayanan S, Sastry M. Nanocrystalline $\mathrm{TiO}_{2}$ studied by optical, FTIR and X-ray photoelectron spectroscopy: correlation to presence of surface states. Thin Solid Films. 2000;358(1-2):122-130.

24. Vorkapic D, Matsoukas T. Effect of Temperature and Alcohols in the Preparation of Titania Nanoparticles from Alkoxides. Journal of the American Ceramic Society. 1998;81(11):2815-2820.

25. Yeh JJ, Lindau I.Atomic subshell photoionization cross sections and asymmetry parameters: $1 \leq \mathrm{Z} \leq 103$. Atomic Data and Nuclear Data Tables.1985;32(1):1-155.

26. Tanuma S, Powell CJ, Penn DR. Calculations of electron inelastic mean free paths. V. Data for 14 organic compounds over the 50-2000 eV range. Surface and Interface Analysis. 1994;21(3):165-176.

27. Karami A. Synthesis of $\mathrm{TiO}_{2}$ nano powderby the sol-gel method and its use as a photocatalyst. Journal of the Iranian Chemical Society. 2010;7(2 Suppl):S154-S160.

28. Look JL, Zukoski CF. Colloidal Stability and Titania Precipitate Morphology: Influence of Short-Range Repulsions. Journal of the American Ceramic Society. 1995;78(1):21-32.

29. Nagpal VJ, Davis RM, Riffle JS. In situ steric stabilization of titanium dioxide particles synthesized by a sol-gel process. Colloids and Surfaces A: Physicochemical and Engineering Aspects.1994;87(1):25-31.

30. Shirley DA. High-Resolution X-Ray Photoemission Spectrum of the Valence Bands of Gold.Physical Review B. 1972;5(12):4709-4713.

31. Arami H, Mazloumi M, Khalifehzadeh R, Sadrnezhaad SK. Sonochemical preparation of $\mathrm{TiO}_{2}$ nanoparticles. Materials Letters. 2007;61(23-24):4559-4561.

32. Borgese L, Bontempi E, Gelfi M, Depero LE, Goudeau P, Geandier G, et al. Microstructure and elasticproperties of atomiclayerdeposited $\mathrm{TiO}_{2}$ anatasethin films. Acta Materialia. 2011;59(7):2891-2900.

33. Shu-Xin W, Zhi M, Yong-Ning Q, Fei H, Li Shan J, Yan-Jun Z. XPS study of Cooper dopping $\mathrm{TiO}_{2}$ photocatalyst. Acta Physico-Chimica Sinica. 2003;19(10):967-969.

34. Fang J,Bi X, Si D, Jiang Z, Huang W. Spectroscopic studies of interfacial structures of $\mathrm{CeO}_{2}-\mathrm{TiO}_{2}$ mixed oxides. Applied Surface Science. 2007;253:8952-61.

35. Naumkin AV, Kraut-Vass A, Gaarenstroom SW, Powell CJ. NIST X-Ray Photoelectron Spectroscopy Database 20,Version 4.1. Washington: U.S. Secretary of Commerce; 2012.

36. Moulder JF, Stickle WF, Sobol PE, Bomben KD. Handbook of X-ray photoelectron spectroscopy: a reference book of standard spectra for identification and interpretation of XPS data. Eden Prairie: Physical Electronics Division,Perkin-Elmer Corp; 1992. 261 p. 